\title{
Comparison of in situ methods to assess DNA cleavage in apoptotic cells in patients with breast cancer
}

P N Mainwaring, P A Ellis, S Detre, I E Smith, M Dowsett

\begin{abstract}
Background-Apoptosis has a role in many cellular processes including development, normal tissue homeostasis, and malignancy. This aspect of research is relatively new with distinct methods of analysing disparate biochemical and genetic events to measure apoptotic cells. The use of biotinylated nucleotides to identify DNA strand breaks is a commonly reported method of estimating cells numbers undergoing apoptosis; however, investigators report inconsistent results for a variety of reasons.

Aims and method-To compare two in situ techniques of measuring apoptosis: in situ nick translation (ISNT) and TdT mediated dUTP-biotin nick end labelling (TUNEL); and to assess DNA cleavage in 20 paired paraffin wax embedded breast cancer tissues from patients; one group who had received no prior treatment and one group who had received chemohormonal treatment.

Results and conclusions-Apoptotic scores obtained from paraffin wax embedded human breast cancer after using ISNT and TUNEL methods were not significantly different $(p=0.11)$. A strong correlation between scores obtained from the two techniques was found $(r=0.758$, $p<0.0001)$. Optimisation of both techniques is crucial to ensure maximal assay performance in breast cancer tissue. (F Clin Pathol 1998;51:34-37)
\end{abstract}

Keywords: apoptosis, in situ nick translation; TUNEL; in situ end labelling; breast cancer

In vitro and in vivo evidence strongly points to induction of apoptosis as the primary mechanism by which malignant breast cells die in response to systemic treatment. ${ }^{12}$ The current, most widely accepted standard for measuring apoptosis in vivo involves light microscopic evaluation using criteria established in the original descriptions of this mode of cell death. ${ }^{34}$ Time lapse studies show that induction of apoptosis may take as little as 1-3 hours and apoptotic cells and bodies may appear for only a few minutes to hours before they are phagocytosed. ${ }^{45}$ Thus cells that are recognisably apoptotic on morphological criteria are relatively scarce in tissue sections and labourious to count on slides using conventional stains. In addition to cell shrinkage, apoptosis is characterised by chromatin condensation and nuclear fragmentation. Investigations are cur- rently in progress dissecting the order of molecular and biochemical events associated with programmed cell death. A broad spectrum of cell lines grown under different culture conditions have implicated cleavage of double stranded DNA, in some cases by endogenous $\mathrm{Ca}^{++} / \mathrm{Mg}^{++}$endonucleases, into oligonucleosomal fragments, as an event indicating irreversible commitment to apoptosis. ${ }^{6}$

In response to the scarcity of apoptotic cells and difficulties in recognition and counting, two other methods have been described to label DNA breaks in nuclei. ${ }^{78}$ These methods have eased detection of apoptosis by light microscopy. One method, the TUNEL assay, is based on incorporating biotinylated deoxyuridine (b-dUTP) at 3'-OH DNA strand breaks using binding with terminal deoxynucleotidyl transferase (TdT). The other method, known as in situ nick translation (ISNT) or in situ end labelling (ISEL), uses the Klenow fragment of Escherishia coli DNA polymerase I for incorporating the b-dUTP. The former method targets 3' recessed, 5' recessed, and blunt end DNA fragments, while the latter favours recessed 3' ends.

There has been a major increase in the number of studies of apoptosis, and the application of these two techniques. The TUNEL assay has proved popular because of the availability of a kit form. In one study measuring induction of apoptosis by flow cytometry the kinetics of biotinylated dUTP incorporation was faster and the distinction of cells with DNA breaks was more pronounced using TUNEL $^{9}$; in the other TUNEL was reported to demonstrate apoptotic cells in breast cancer tissues while ISNT did not. ${ }^{10}$ In contrast, our experience in uncontrolled studies indicated that the two techniques may be similar in identifying cells undergoing apoptosis. We therefore conducted a controlled comparative study of these two approaches for the detection of cells committed to apoptosis to aid us and others in choice of technique.

\section{Material and methods}

Formalin fixed, paraffin wax embedded breast cancer tissues from two patient groups were analysed. One group had surgical excision of their disease without prior chemotherapy. The other underwent primary or neoadjuvant chemohormonal treatment, comprising methotrexate, mitoxantrone, and tamoxifen (MMT), before resection of residual disease as part of a recently reported randomised study. ${ }^{11}$

Two sets of 20 breast carcinomas, one set before and one after three months of 

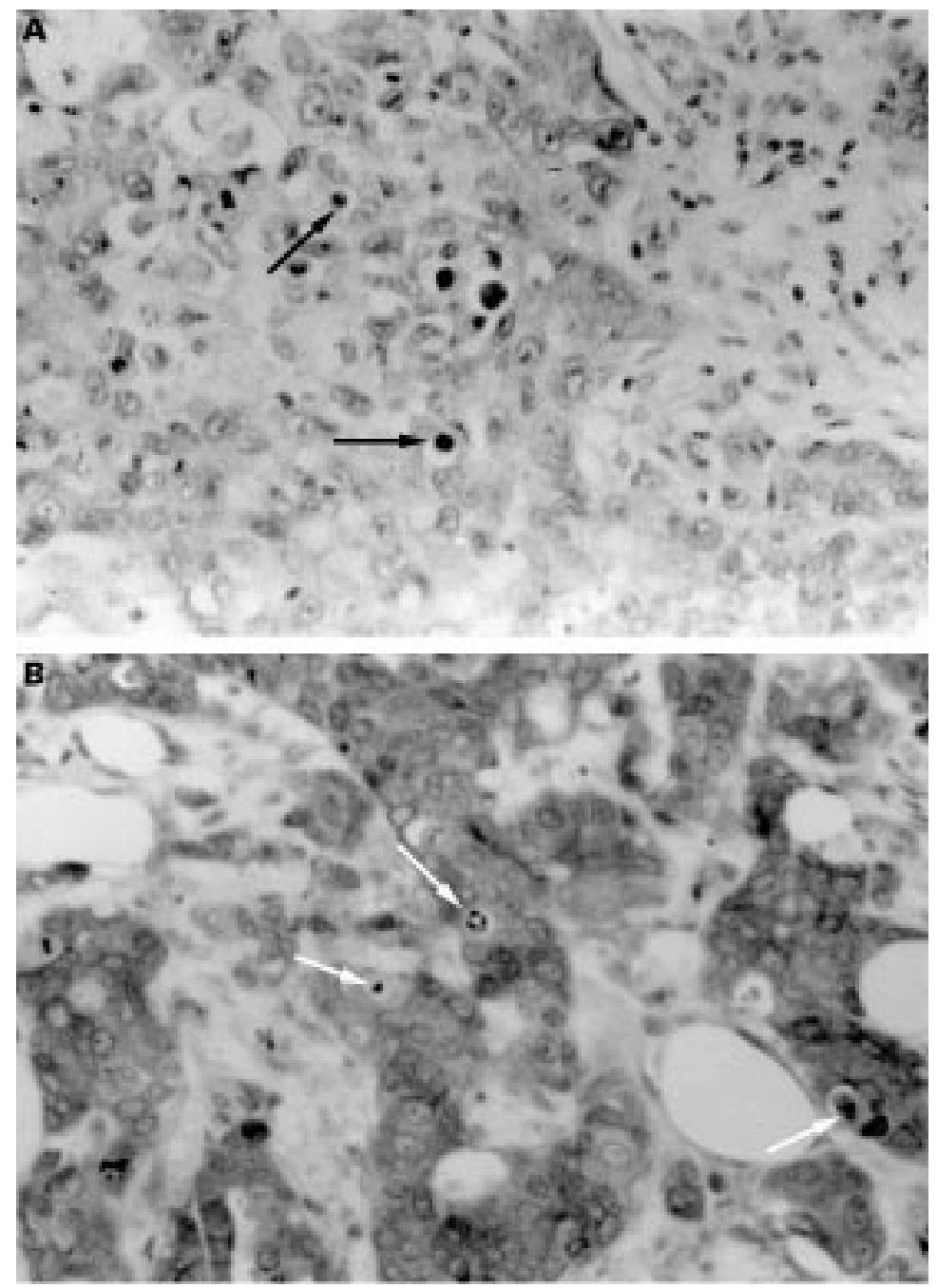

Figure 1 Staining to measure apoptotic cells from breast cancer tissue using (A) ISNT and (B) TUNEL. Note the difference in background staining. Arrows, apoptotic cells. (Original magnification $\times 400$.) combination chemohormonal treatment, were randomly selected from our histopathology stores. Pairs of $3 \mu \mathrm{m}$ sections were cut, deparaffinised, and taken through progressively decreasing concentrations of industrial methylated spirit to double distilled water (DDW). Endogenous peroxidase activity was inactivated with $1 \%$ hydrogen peroxide in phosphate buffered saline (PBS) pH 7.4, for 10 minutes. Nuclei of tissue sections were stripped of proteins by incubation with $0.5 \%$ pepsin, pH 2, (Sigma Chemical Co, Poole, Dorset, UK) for 30 minutes at $37^{\circ} \mathrm{C}$. The sections were washed five times in DDW to remove all traces of pepsin.

Each section undergoing the TUNEL protocol was incubated for five minutes in Tris buffer, $\mathrm{pH} 7.6$, and then for one hour at $37^{\circ} \mathrm{C}$ in $100 \mu \mathrm{l}$ of reaction mixture consisting of 15 units TdT FPLC pure (Pharmacia, Windsor, Berkshire, UK), $0.5 \mathrm{nmol}$ biotin-16-dUTP (Boehringer Mannheim, Mannheim, Germany), $5 \mathrm{mM}$ cobalt chloride, $0.2 \mathrm{M}$ sodium cacodylate, $25 \mathrm{mM}$ Tris $\mathrm{HCl}, \mathrm{pH} 6.6$, and $0.25 \mathrm{mg} / \mathrm{ml}$ bovine serum albumin (BSA), fraction $\mathrm{V}$, dissolved in DDW.
Each section undergoing ISNT was incubated for five minutes in reaction buffer comprising $0.01 \mathrm{mM}$ each of dATP, dGTP, dCTP (Pharmacia), $50 \mathrm{mM}$ trizma base, pH 7.5, $5 \mathrm{mM}$ magnesium chloride, $10 \mathrm{mM} \beta$ mercaptoethanol, density $1.12 \mathrm{~g} / \mathrm{ml}$ (Sigma), and $0.05 \mathrm{mg} / \mathrm{ml} \mathrm{BSA}$ dissolved in DDW. The reaction buffer was then replaced with $100 \mu \mathrm{l}$ of a reaction mixture consisting of 0.4 units of labelling grade Klenow fragment from DNA polymerase 1 (Boehringer Mannheim) plus $0.05 \mathrm{nmol}$ biotin-16-dUTP added to the reaction buffer. The sections were incubated with reaction mixture for two hours at $37^{\circ} \mathrm{C}$.

After extensive washing in DDW all the sections were incubated for 30 minutes at room temperature in $1 / 400$ dilution of horseradish peroxidase conjugated to streptavidin (Dako, High Wycombe, Bucks, UK) in PBS supplemented with $1 \%$ BSA and $0.5 \%$ Tween 20 . Colour was developed for 10 minutes using $0.05 \%$ diaminobenzidine plus $0.07 \%$ imidazole plus $0.1 \%$ hydrogen peroxide, and further intensified in $0.5 \%$ copper sulphate with $0.9 \%$ sodium chloride for one minute. The sections were counterstained in Mayer's haematoxylin, dehydrated, cleared in xylene, and mounted in DPX.

The slides were separately scored by two observers using a double headed eyepiece attachment to a Nikon microscope. With the aid of a graticule within an eyepiece, three thousand malignant cells $( \pm 1 \%)$ were counted at $\times 400$ magnification, taking approximately 30 minutes per slide. In slides where there was disagreement in the scores exceeding $15 \%$ the slide was rescored by both observers and a mean of the two scores for each observer recorded (six slides being rescored). Stained apoptotic cells were recorded and cells displaying classic apoptotic morphology but not staining (always $<30 \%$ of the stained apoptotic cells/section, and generally $<15 \%$; mean $5.2 \%$ ) were also incorporated in the apoptotic index. Non-staining apoptotic cells were recognised in the midst of cells with normal morphology by having either condensed, irregular nuclei frequently with a crescent shaped appearance, or fragmented nuclei within cells showing cytoplasmic withdrawal, resulting in a halo-like effect. Areas with extensive necrosis were avoided. Otherwise, different fields of view were assessed at convenience.

Statistical analyses assumed a skewed distribution and were therefore non-parametric. Correlations were analysed using Spearman rank correlation and paired comparisons using the Wilcoxon signed-rank test. All analyses were performed using the Statview v4.5 statistical program (Abacus Concepts, Berkeley, California, USA).

\section{Results}

All tumours were histologically infiltrating ductal carcinomas. Of the 40 patients' tissue sections selected for study, two patients from the MMT treated group were not suitable for analysis, one set because of inadequate residual breast cancer and another because extensive ductal carcinoma in situ predominated over 
Table 1 Apoptotic scores of breast cancer tissues

\begin{tabular}{lll}
\hline & ISNT & TUNEL \\
\hline $\begin{array}{l}\text { Untreated group (median) } \\
\text { (range) }\end{array}$ & $0.41 \%$ & $0.49 \%$ \\
& $(0.04-2.44 \%)$ & $(0.07-2.64 \%)$ \\
$\begin{array}{l}\text { MMT group (median) } \\
\text { (range) }\end{array}$ & $0.39 \%$ & $0.47 \%$ \\
Overall & $(0.03-2.03 \%)$ & $(0.06-2.03 \%)$ \\
& $0.41 \%$ & $0.48 \%$ \\
& $(0.03-2.44 \%)$ & $(0.06-2.64 \%)$ \\
\hline
\end{tabular}

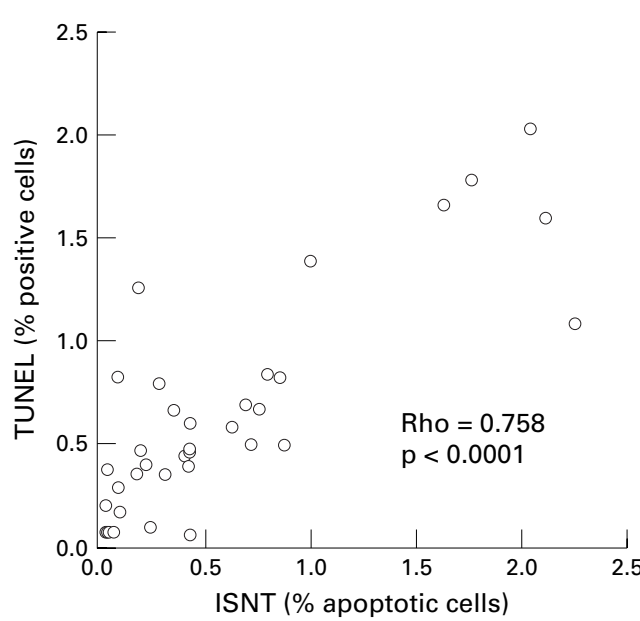

Figure 2 Scattergram of apoptotic scores.

few invasive malignant cells. The median size of invasive disease recorded in the histology reports was $2.0 \mathrm{~cm}$ (range $0.6-8 \mathrm{~cm}$ ) overall; $2.3 \mathrm{~cm}$ (range $0.9-3.5 \mathrm{~cm}$ ) in the untreated patients; and $1.8 \mathrm{~cm}$ (range $0.9-8 \mathrm{~cm}$ ) in patients who had received MMT.

There was a difference in background staining between the two techniques however this did not affect the ability to interpret and score the malignant cells (fig 1). The median apoptotic scores and ranges are shown in table 1. There was no significant difference in apoptotic scores between sections scored with the ISNT technique and those scored with the TUNEL technique overall ( $\mathrm{p}=0.11)$, or in the adjuvant and neoadjuvant groups considered separately $(\mathrm{p}=0.20$ and $\mathrm{p}=0.33$, respectively). A strong correlation between scores was demonstrated between the two techniques overall ( $r=0.758, \mathrm{p}<0.0001$ ) (fig 2). Comparisons between the groups treated with adjuvant compared to primary/neoadjuvant therapy were not made.

\section{Discussion}

The rate of growth of a tumour is a balance between the rate of proliferation and the rate of cell death. We have demonstrated that this balance is altered in postmenopausal women with breast cancer treated with tamoxifen ${ }^{12}$ as well as demonstrating an increase in apoptotic index within 24 hours of starting chemotherapy. ${ }^{1}$ In this small study we have shown that the two commonly used methods to identify apoptotic cells in paraffin wax embedded tissue of patients with breast cancer provide similar indices. No factor, including technical and cost, was identified that would lead to one being recommended over the other. The inability to demonstrate a difference between the two techniques may have been because insufficient samples were analysed. However, the strong correlation coefficient between these techniques suggests that expanding the sample size would identify only minor differences.

It is unclear why certain individual cells show classic apoptotic morphology but no staining (a phenomenon that was observed to essentially the same extent with both techniques). It is known, however, that certain cells can proceed through apoptosis while generating DNA fragments of about 50000 base pairs with no evidence of the classic 180 base pair fragments. ${ }^{13}$ Cells containing such large fragments only would have about $1 / 250$ the staining of those with smaller fragments only, and would appear essentially unstained using the TUNEL or ISNT methods. Even with some cells not staining the much easier resolution of cells that do stain as apoptotic makes the application of the staining technology worthwhile. Cells that stained but did not show all the features of apoptotic cells were scored under the rationale that the molecular technology may have a "lead time" in relation to morphological changes, and that the increased sensitivity this would yield would be helpful.

We believe that staining for apoptosis is beneficial for three reasons. First, to improve recognition of cells without morphological criteria of apoptosis; second, as a comparison when other immunohistochemical markers for the apoptotic cascade in paraffin wax embedded tissue become available; and third, potentially to play a role in automated counting. Potential causes of false positive staining include regions of necrosis and non-cellular debris. Consequently, areas of necrosis were avoided by at least one high powered field. Furthermore, areas containing ductal carcinoma in situ were not included in the analysis. Groups of small apoptotic bodies, which may be confused with debris, were counted as a single event. Discrimination between malignant breast cancer cells and cells of other tissue origin undergoing apoptosis is not possible. Only positive cells in regions of malignant disease were counted to minimise any potential error. Some reports imply that apoptotic cells may congregate in regions; however, we did not observe this feature.

Investigators have reported differences in the identification and scoring of cells undergoing apoptosis using the same methods as we have used. Gorczyca and colleagues measured DNA strand breaks in HL-60 cells induced by treatment with the DNA topoisomerase I inhibitor camptothecin, and topoisomerase II inhibitors teniposide and fostriecin. ${ }^{9}$ The kinetics of b-dUTP incorporation was faster, and the distinction of cells with DNA breaks was more pronounced in cells incorporating b-dUTP with TUNEL than with ISNT, using bivariate flow cytometric analysis.

Mundle and colleagues reported comparable apoptotic indices determined by ISNT and TUNEL in plastic embedded tissues from patients with non-Hodgkin's lymphoma, squamous cell carcinoma from the head and 
neck, and mononuclear cell cultures from patients with myelodysplastic syndromes, but not in breast cancer tissues whether neoplastic, normal or metastatic, in HL-60 cultured cells treated with etoposide or serum-starved A549 lung carcinoma cells. ${ }^{10}{ }^{14}$ Mean apoptotic indices in double labelled myelodysplastic cultured cells, ISNT and TUNEL, were comparable to those in single labelled cells in each case. In contrast, serum starved A549 lung carcinoma cells demonstrated apoptosis detectable only by TUNEL and not by ISNT in single and double labelling experiments. These authors have hypothesised that specific fragmentation patterns could be a result of activation of different endonucleases that could be tissue specific and may be differentially activated by different chemotherapeutic agents. ${ }^{10} 14$ These differences would then be reflected in the staining patterns of apoptotic cells because of the different specificities for DNA cleavage by the enzymes involved, potentially leading to major differences in the estimation of apoptosis according to the method employed, the disease/tissue studied, and the treatment context.

We chose to assess treated and untreated tumours so that the possibility could be evaluated that apoptosis occurring during chemotherapy might yield apoptotic cells that rendered them systematically more sensitive to staining by one or the other method. Our finding of good correlation between the two techniques in both untreated and treated breast carcinomas, with the treatment involving cytotoxic and hormonal agents, suggests that any such differences are unlikely to have a significant impact on estimations made in breast carcinomas. It should be noted that we would not necessarily expect the apoptotic score to be higher than pretreatment values after three months' treatment as the resected disease may be chemoresistant by that time.

In preparation for our study we, like others, ${ }^{15}$ found that optimising protein cross linking digestion in paraffin wax embedded tissues clearly influenced our efforts to minimise background staining while maximising that of apoptotic cells. To circumvent problems associated with proteolytic treatment of paraffin wax embedded tissues Panchalingham and colleagues reported pretreatment by pressure cooking before assessment of apoptotic cells using ISNT and TUNEL. ${ }^{16}$ Using this method they obtained similar results between sections stained with ISNT or TUNEL in tissues from patients with Burkitt's lymphoma. ${ }^{16}$ Two studies on human brain tissue have reported reduction of apoptotic index counts with prolonged formalin fixation and reversal of this loss with microwave pretreatment. ${ }^{17}{ }^{18} \mathrm{~A}$ recent paper has reported that using higher magnifications of tissue sections, stained with haematoxylin and eosin, increased correlation coefficients of intraobserver and interobserver apoptotic cell counts. ${ }^{19}$ It is therefore possible that reports of poor performance of ISNT relative to TUNEL may have been, at least in part, due to the absence of full optimisation of the ISNT technique.

Until further studies elucidate the critical initial steps in commitment to apoptosis and until techniques are developed to identify these, light microscopic evaluation of apoptotic cells is expected to remain the in vivo standard for solid tissue analyses. Both TUNEL and ISNT provide a valuable aid in conducting such evaluation and appear to be essentially equivalent in the results derived.

1 Ellis PA, Smith IE, McCarthy K, Detre S, Salter J, Dowsett $M$. Preoperative chemotherapy induces apoptosis in early breast cancer [letter]. Lancet 1997;349:84

2 Dive C, Evans CA, Whetton AD. Induction of apoptosisnew targets for cancer chemotherapy. Semin Cancer Biol 1992;3:417-27.

3 Kerr JF, Wyllie AH, Currie AR. Apoptosis: a basic biological phenomenon with wide-ranging implications in tissue kinetics. Br 7 Cancer 1972;26:239-57.

4 Wyllie AH, Kerr JF, Currie AR. Cell death: the significance of apoptosis. Int Rev Cytol 1980;68:251-306.

5 Wyllie AH. Apoptosis and the regulation of cell numbers in normal and neoplastic tissues: an overview. Cancer Metastasis Rev 1992;11:95-103.

6 Wyllie AH. Glucocorticoid-induced thymocyte apoptosis is associated with endogenous endonuclease activation. $\mathrm{Na}$ ture 1980;284:555-6.

7 Gavrieli Y, Sherman Y, Ben SS. Identification of programmed cell death in situ via specific labeling of nuclea DNA fragmentation. $\mathcal{F}$ Cell Biol 1992;119:493-501.

8 Wijsman JH, Jonker RR, Keijzer R, van dVC, Cornelisse CJ, van DJ. A new method to detect apoptosis in paraffin
sections: in situ end-labeling of fragmented DNA. $\mathscr{F}$ Histochem Cytochem 1993;41:7-12.

9 Gorczyca W, Gong J, Darzynkiewicz Z. Detection of DNA strand breaks in individual apoptotic cells by the in situ terminal deoxynucleotidyl transferase and nick translation assays. Cancer Res 1993;53:1945-51.

10 Mundle SD, Gao XZ, Khan S, Gregory SA, Preisler HD, Raza A. Two in situ labeling techniques reveal different patterns of DNA fragmentation during spontaneous apoppatterns of DNA fragmentation during spontaneous apop-
tosis in vivo and induced apoptosis in vitro. Anticancer Res tosis in vivo and ind

11 Powles TJ, Hickish TF, Makris A, et al. Randomized trial of chemoendocrine therapy started before or after surgery for treatment of primary breast cancer. $\mathcal{F}$ Clin Oncol 1995;13: 547-52.

12 Dowsett M, Johnston S, Newby J, Golding M, Sacks N, Smith I. Mechanisms of hormone response: a role for apoptosis. Endocrine-related Cancer 1995;2:3-11.

13 Oberhammer F, Wilson JW, Dive C, et al. Apoptotic death in epithelial cells: cleavage of DNA to $300 \mathrm{and} /$ or $50 \mathrm{~kb}$ fragments prior to or in the absence of internucleosomal fragments prior to or in the absence of intern

14 Mundle S, Joshi I, Uhal B, et al. In situ double-labeling with two enzymatic reactions to distinguish specific DNA fragmentation patterns in apoptotic cell death [abstract]. Proceedings of the Annual Meeting of the American Association of Cancer Research, 1996.

15 Strater J, Gunthert AR, Bruderlein S, Moller P. Microwave irradiation of paraffin-embedded tissue sensitizes the TUNEL method for in situ detection of apoptotic cells. Histochem Cell Biol 1995;103:157-60.

16 Panchalingham S, Reynolds G, Lammas D, Kumararatne D. Simple method for pretreatment of tissue sections for the detection of apoptosis by in situ end-labelling and in situ nick translation. $\mathcal{F}$ Clin Pathol: Mol Pathol 1996;49: M273-7.

17 Lucassen PJ, Chung WC, Vermeulen JP, Van Lookeren Campagne $M$, Van Dierendonck $C$, Swaab DF. Microwave-enhanced in situ end-labeling of fragmented DNA: parametric studies in relation to postmortem delay and fixation of rat and human brain. 7 Histochem Cytochem 1995;43:1163-71.

18 Davison FD, Groves M, Scaravilli F. The effects of formalin fixation on the detection of apoptosis in human brain by in situ end-labelling of DNA. Histochem $\mathcal{F}$ 1995;27:983-8.

19 Van de Schepop H, De Jong J, Van Diest P, Baak J. Counting of apoptotic cells: A methodological study in invasive breast cancer. F Clin Pathol: Mol Pathol 1996;49:M214-17. 